\title{
Chronic kidney disease and positive surgical margins as prognosticators for upper urinary tract urothelial carcinoma patients undergoing radical nephroureterectomy
}

\author{
KENJI KURODA, JUNICHI ASAKUMA, AKIO HORIGUCHI, MAKOTO KAWAGUCHI, \\ MASAYUKI SHINCHI, AYAKO MASUNAGA, SHINSUKE TASAKI, AKINORI SATO and KEIICHI ITO \\ Department of Urology, National Defense Medical College, Tokorozawa, Saitama 359-8513, Japan
}

Received September 24, 2018; Accepted March 18, 2019

DOI: $10.3892 / \mathrm{mco} .2019 .1829$

\begin{abstract}
Chronic kidney disease (CKD) is a common condition among elderly patients and has been reported to be a biomarker for the presence of malignant disease. In addition, unfavorable outcomes for patients with upper tract urothelial carcinoma (UTUC) undergoing radical nephroureterectomy can be due to independent clinical factors. Therefore, the present study analyzed the clinicopathological data of patients with UTUC, who underwent radical nephroureterectomy at our institution, to clarify whether preoperative CKD and other factors are independent predictors of the shorter disease-specific and/or recurrence-free survival time of these patients. A retrospective review of 187 patients who underwent radical nephroureterectomy was conducted, and patients were followed for at least 3 months postoperatively. The clinicopathological factors that are thought to have potentially significant roles in the progression and metastasis of malignant tumors and for disease-specific and recurrence-free survival were evaluated. Positive surgical margins and an estimation of the glomerular filtration rate (eGFR) of $<60$ were independent factors for the shorter disease-specific survival time in multivariate analysis with Cox's proportional hazards model [hazard ratio (HR), 2.401: 95\% confidence interval (CI), 1.044-5.255; and HR, 2.371: 95\% CI, 1.024-5.898, respectively]. Another multivariate analysis also revealed that positive surgical margins (HR, 4.477; 95\% CI, 2.042-9.469), and preoperative eGFR $<60$ (HR, 2.362; 95\% CI, 1.067-5.592) were independent factors for the worse recurrence-free survival rate in all patients. Patients with UTUC who had eGFR $<60$ as well as positive surgical margins had significantly shorter time to disease-specific mortality and extraurothelial recurrence. The
\end{abstract}

Correspondence to: Dr Kenji Kuroda, Department of Urology, National Defense Medical College, 3-2 Namiki, Tokorozawa, Saitama 359-8513, Japan

E-mail: kksmy@sa2.so-net.ne.jp

Key words: upper urinary tract, urothelial carcinoma, chronic kidney disease, surgical margins, prognosis present study demonstrated that patients with UTUC undergoing radical nephroureterectomy who have CKD as well as positive surgical margins should be carefully followed up postoperatively.

\section{Introduction}

Urothelial carcinoma (UC) is a heterogeneous group of malignant tumors that develop in the lower urinary tract (UT) (bladder and urethra) or in the upper UT (renal pelvis and ureter). Bladder tumors account for $90-95 \%$ of UCs and are the most common cancers of the urinary tract (1). In contrast, UTUCs are rare and account for only 5-10\% of UCs $(2,3)$. Renal pelvic tumors are twice as frequent as ureteral tumors (4). About $17 \%$ of UTUC patients have concurrent bladder cancer. Intravesical recurrence occurred in $22-47 \%$ of UTUC patients versus 2-6\% in the contralateral upper UT (5-7).

Chronic kidney disease (CKD) is common among elderly patients and has been associated with malignant disease $(8,9)$. In addition, CKD is particularly associated with cancers of the kidneys and urinary tract (10). In our previous report, we evaluated the prognostic factors for ureteral carcinoma, and found that the estimated glomerular filtration rate (eGFR) of $<60 \mathrm{ml} / \mathrm{min} / 1.73 \mathrm{~m}^{2}$ was one of the preoperative predictive factors of extraurothelial recurrence as well as that of positive cytology, clinical $\mathrm{T}$ at stage $\geq 3$, and the length of ureteral cancer $3 \mathrm{~cm}$ in patients with ureteral carcinoma (11). Identification of predictors, including CKD, enabled the selection of candidates for neoadjuvant chemotherapy and/or to decide whether extended lymphadenectomy should be performed during radical nephroureterectomy (11).

However, to date, no report has suggested any prognostic association of preoperative CKD with oncological outcomes such as worse disease-specific and/or recurrence-free survival rates in patients with the cancers of the renal pelvis or the ureter. Therefore, it is imperative to investigate the role of preoperative CKD as a prognostic factor in patients with whole UTUC. Our previous findings suggest that CKD could be a promising prognostic factor for poor prognosis in patients with not only ureteral cancer but also whole UTUC.

In addition, the relatively poor outcomes of patients with localized UTUC undergoing radical nephroureterectomy are 
influenced by factors such as more aggressive tumor biology, lymphovascular invasion, or lymph node metastasis $(12,13)$. Therefore, we speculate that patients with UTUC who have some clinical factors and CKD could have even worse survival rates than those with either condition. Herein, we retrospectively analyzed the clinicopathological data of patients with UTUC who underwent radical nephroureterectomy at National Defense Medical College (single center). We aimed to clarify whether preoperative CKD as well as other pathological factors are independent predictors of shorter disease-specific and/or recurrence-free survival time in patients with UTUC.

\section{Patients and methods}

Patients. We retrospectively reviewed clinicopathological data from the medical records of 187 N0M0 UTUC patients who underwent radical nephroureterectomy and were histologically diagnosed with urothelial carcinoma between March 1999 and March 2017. The retrospective data used to support the findings of this study are included within the article. The study protocol (ID 2734) was accepted on June 14, 2017, by our Institutional Ethics Committee (National Defense Medical College), and an opt-out approach on the web page of the National Defense Medical College was used instead of collecting written informed consent from all participants. A total of 138 men and 49 women of median age 71 years (range: $38-90$ years) were included in the present study. The mean follow-up period after surgery was 49.2 months (range: 3.4-209.2 months). Table I shows the additional clinicopathological data.

Overall, 104 patients were treated by open nephroureterectomy, while 83 were treated by laparoscopic nephroureterectomy. 47 patients had a history of bladder cancer. Regional lymphadenectomy was performed in 57 patients, and extended lymph node dissection was not routinely performed. The method of lymphadenectomy was the same as that described in our previous paper (11). Of the 57 patients who underwent regional lymphadenectomy, 15 had positive lymph node metastasis. Neoadjuvant chemotherapy was administered in four patients, of which two patients developed postoperative recurrence or distant metastasis. Adjuvant chemotherapy was performed in 53 patients with histologically confirmed lymph node involvement or pathologically stage T3 or higher cancer, of which 30 patients developed recurrence and/or distant metastasis. We used a combination of cisplatin and gemcitabine as the chemotherapy regimen for all patients undergoing neoadjuvant or adjuvant chemotherapy. We adjusted the dose of cisplatin according to the renal function of patients undergoing neoadjuvant or adjuvant chemotherapy. Local recurrence or distant metastasis was monitored for each patient every 3-6 months for the first 5 years after surgery and 6-12 months thereafter.

All the surgical specimens were processed according to the standard pathological procedures and were histologically confirmed to be urothelial carcinoma with or without other tumor cell types. The pathological staging of the primary tumor (pT) was assessed according to the American Joint Committee on Cancer Tassification (14), whereas tumor grading was performed according to the 2004 WHO classification of urothelial tumors (15). Tumor slides were evaluated by two pathologists, and patients were divided into two groups on the basis of the 2004 WHO classification system for tumor grading.

Inflammatory indices. Inflammatory indices were evaluated by laboratory tests. The neutrophil to lymphocyte ratio (NLR) was calculated by dividing the absolute neutrophil count by the absolute lymphocyte count (16). The platelet to lymphocyte ratio (PLR) was calculated by dividing the absolute platelet count by the absolute lymphocyte count (16). The C-reactive protein (CRP) to albumin (Alb) ratio (CAR) was calculated by dividing the CRP value by Alb value. The Glasgow prognostic score (GPS) was evaluated by using the CRP and Alb values. Patients with elevated CRP levels $(>1 \mathrm{mg} / \mathrm{dl})$ in combination with hypoalbuminemia $(<3.5 \mathrm{~g} / \mathrm{dl})$ were allocated 2 points. Patients with elevated CRP alone or hypoalbuminemia alone were allocated 1 point, whereas patients exhibiting these parameters within normal limits were allocated 0 points (17). In addition, serum fibrinogen levels acted as inflammatory markers in the present study.

The following formula was used for the estimation of glomerular filtration rate (eGFR) by computation: eGFR $\left(\mathrm{ml} / \mathrm{min} / 1.73 \mathrm{~m}^{2}\right)=194 \mathrm{x}$ (serum creatinine $)^{-1.094} \times \operatorname{Age}^{-0.287} \mathrm{x}(0.739$, for women).

This formula is a modified study equation of the Japanese Society of Nephrology-Chronic Kidney Disease Initiatives (JSN-CKDI) coefficient from the isotope dilution mass spectrometry (IDMS)-traceable 4-variable Modification of Diet in Renal Disease (MDRD) Study equation. It was reported to be more accurate for hospitalized Japanese patients with eGFR $<60 \mathrm{ml} / \mathrm{min} / 1.73 \mathrm{~m}^{2}$ than the IDMS MDRD Study Equation (18). Laboratory data were measured within a month or two before radical nephroureterectomy.

Statistical analysis. We performed univariate and multivariate analyses by using the Cox proportional hazards model to identify independent factors for shorter disease-specific and recurrence-free survival time. We also performed a receiver operator characteristic(ROC) analysis to determine the cut-off values of eGFR, CAR, NLR, PLR, and fibrinogen levels according to the method shown in previous reports (19-22). We constructed the survival curves by using the Kaplan-Meier method and evaluated the statistical differences among them with the log-rank test. We performed statistical analyses with JMP Pro 11 (SAS Institute, Inc., Cary, NC, USA). P<0.05 was considered to indicate a statistically significant difference.

\section{Results}

Independent prognosticator of worse disease-specific survival rate. $\mathrm{ROC}$ analysis revealed that patients with $\mathrm{eGFR}<60$, CAR $\geq 0.079$, NLR $\geq 2.035$, PLR $\geq 165$, and fibrinogen levels $\geq 337$ had a significantly higher association with disease-specific deaths than patients without these conditions. The ROC curves are shown in Fig. 1A-E. We constructed a Cox proportional hazards model for detecting the independent factors for worse disease-specific survival rate among preoperative clinicopathological factors for the study subjects. Among these factors, in a univariate analysis, positive urine cytology, tumor histology besides urothelial carcinoma, higher $\mathrm{pT}$ stage, 
Table I. Clinicopathological features.

\begin{tabular}{l} 
Parameters \\
\hline Sex \\
Men \\
Women \\
Urine cytology \\
$\geq$ IIIb \\
$\leq$ IIIa \\
Histology \\
UC + differentiation \\
UC alone
\end{tabular}

Patients, $\mathrm{n}$

Pathological T stage

$\geq \mathrm{T} 3$

$\leq \mathrm{T} 2$

Tumor grade

High

PUNLMP/low

Lympho node metastasis

Positive

Negative

Ureteral involvement

Positive

Negative

Surgical margins

Positive

Negative

Lymphovascular invasion

Positive

Negative

History of bladder cancer

Present

Absent

CIS

Present

Absent

Hydronephrosis

Positive

Negative

Postoperative recurrence or metastasis

Positive

Negative

138

49

116

71

38

149

91

96

132

Surgical procedure

Open

Laparoscopic

eGFR

$<60$

$\geq 60$

CAR

$\geq 0.079$

$<0.079$

NLR

$\geq 2.035$

$<2.035$
Table I. Continued.

\begin{tabular}{|c|c|}
\hline Parameters & Patients, $\mathrm{n}$ \\
\hline \multicolumn{2}{|l|}{ PLR } \\
\hline$\geq 165$ & 63 \\
\hline$<165$ & 123 \\
\hline \multicolumn{2}{|l|}{ GPS } \\
\hline$\geq 1$ & 163 \\
\hline 0 & 24 \\
\hline \multicolumn{2}{|c|}{ Fibrinogen $(n=146)$} \\
\hline$\geq 337$ & 45 \\
\hline$<337$ & 101 \\
\hline \multicolumn{2}{|c|}{$\begin{array}{l}\text { UC, urothelial carcinoma; PUNLMP, papillary urothelial neoplasm } \\
\text { of low malignant potential; CIS, carcinoma in situ; eGFR, estimated } \\
\text { glomerular filtration rate }\left(\mathrm{ml} / \mathrm{min} / 1.73 \mathrm{~m}^{2}\right) \text {; CAR, C-reactive protein } \\
\text { to albumin ratio; NLR, neutrophil to lymphocyte ratio; PLR, platelet } \\
\text { to lymphocyte ratio; GPS, Glasgow prognostic score. }\end{array}$} \\
\hline
\end{tabular}

high tumor grade, lymph node metastasis, positive surgical margins, and LVI were found to be independent factors for shortened disease-specific survival time $(\mathrm{P}=0.034, \mathrm{P}=0.002$, $\mathrm{P}<0.001, \mathrm{P}<0.001, \mathrm{P}<0.001, \mathrm{P}=0.004, \mathrm{P}<0.001$, respectively). In addition, in another univariate analysis, preoperative eGFR, CAR, NLR, PLR, GPS, and serum fibrinogen levels acted as independent factors for shortened disease-specific survival time among laboratorial factors $(\mathrm{P}<0.001, \mathrm{P}=0.002$, $\mathrm{P}=0.009, \mathrm{P}=0.008, \mathrm{P}=0.003$, and $\mathrm{P}<0.001$, respectively). Among these factors, positive surgical margins and eGFR $<60 \mathrm{ml} / \mathrm{min} / 1.73 \mathrm{~m}^{2}$ were independent factors for the worse disease-specific survival rate in the multivariate analysis [hazard ratio (HR), 2.401; 95\% confidence interval (CI), 1.044-5.255; $\mathrm{P}=0.040$, and HR, 2.371; 95\% CI, 1.024-5.898; $\mathrm{P}=0.044$, respectively] (Table II).

In fact, the Kaplan-Meier curves and the results of a log-rank test revealed a significant difference in the disease-specific survival rates between patients with and without positive surgical margins and eGFR $<60 \mathrm{ml} / \mathrm{min} / 1.73 \mathrm{~m}^{2}(\mathrm{P}=0.001$, $\mathrm{P}<0.001$, respectively) (Fig. 2A and B).

Independent predictors of worse recurrence-free survival rate. In the univariate analysis, recurrence-free survival, that is extraurothelial-recurrence-free survival, was found to be shorter in patients with tumor histology besides urothelial carcinoma, higher pT stage, high tumor grade, lymph node metastasis, positive surgical margins, and LVI $(\mathrm{P}=0.001$, $\mathrm{P}<0.001, \mathrm{P}<0.001, \mathrm{P}<0.001, \mathrm{P}=0.001, \mathrm{P}<0.001$, respectively). In addition, in another univariate analysis, preoperative eGFR, CAR, NLR, PLR, GPS, and serum fibrinogen levels acted as independent factors for shortened recurrence-free survival time among laboratorial factors $(\mathrm{P}<0.001, \mathrm{P}=0.004, \mathrm{P}=0.040$, $\mathrm{P}=0.019, \mathrm{P}=0.003$, and $\mathrm{P}<0.001$, respectively). Among these factors, high tumor grade, positive surgical margins, LVI, and preoperative eGFR $<60 \mathrm{ml} / \mathrm{min} / 1.73 \mathrm{~m}^{2}$ were found to act as independent factors for worse recurrence-free survival rate in all patients included in the multivariate analysis 
A

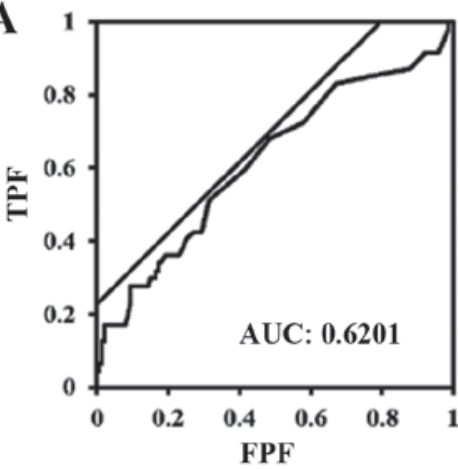

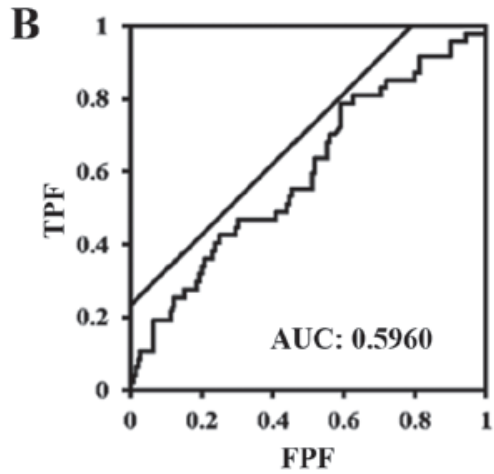
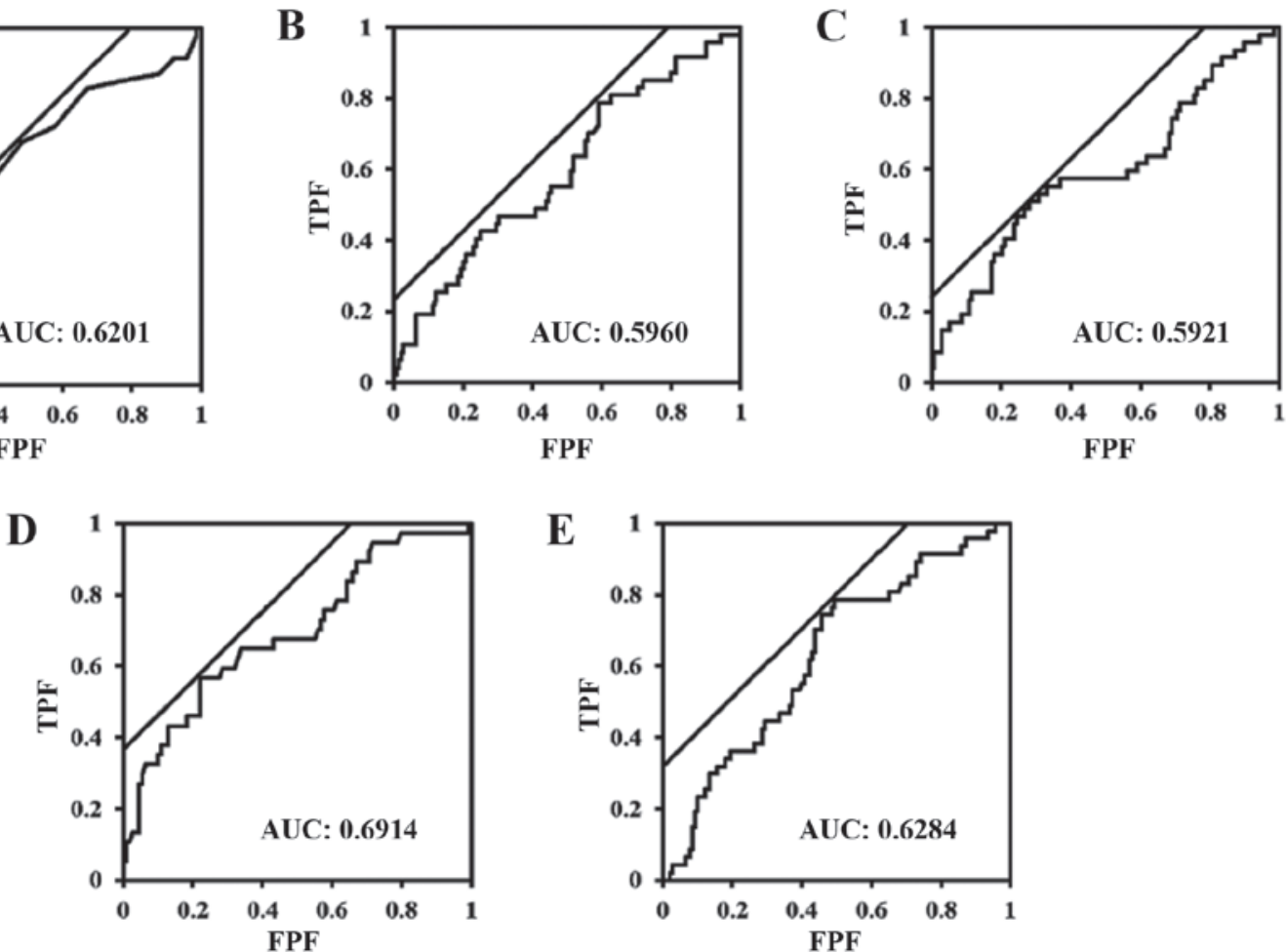

Figure 1. There was a significant association between (A) albumin ratio, (B) neutrophil to lymphocyte ratio, (C) platelet to lymphocyte ratio, (D) fibrinogen levels, and (E) estimation of the glomerular filtration rate with disease-specific mortality $(\mathrm{P}=0.030, \mathrm{P}=0.036, \mathrm{P}=0.011, \mathrm{P}<0.001, \mathrm{P}=0.024$, respectively). The values of the farthest points from a diagonal from the lower left to the upper right (the tangent points at which the black diagonal line contacts with ROC curve) are (A) 0.079 , (B) 2.035, (C) 164.697, (D) 337, and (E) 61.77. TPF, true positive fraction; FPF, false positive fraction; AUC, area under the curve.

(HR, 2.934; 95\% CI, 1.069-9.570; $\mathrm{P}=0.036$, and HR, 4.477; 95\% CI, 2.042-9.469; $\mathrm{P}<0.001$, and HR, 2.615; 95\% CI, 1.180-5.969; $\mathrm{P}=0.018$, and $\mathrm{HR}, 2.362 ; 95 \% \mathrm{CI}, 1.067-5.592$; $\mathrm{P}=0.034$, respectively) (Table III).

The Kaplan-Meier curves and the results of the log-rank test both revealed a significant difference in the recurrence-free survival rates between patients with and without high tumor grade, positive surgical margins, LVI, and preoperative eGFR $<60 \mathrm{ml} / \mathrm{min} / 1.73 \mathrm{~m}^{2}$ (both $\mathrm{P}<0.001$ ) (Fig. 3A and B).

Survival rates in patients with stratified risks. From the aforementioned findings, positive surgical margins and eGFR $<60$ were found to be independent predictors of worse disease-specific and recurrence-free survival rates. We stratified patients according to the number of independent factors and we used Kaplan-Meier curves and the results of the log-rank test to analyze survival rates. There was a significant difference in disease-specific and recurrence-free survival rates between patients with both positive surgical margins and eGFR $<60$, those with either factor, and those with neither factor (both $\mathrm{P}<0.001$ ) (Fig. $4 \mathrm{~A}$ and $\mathrm{B}$ ).

\section{Discussion}

In the present study, preoperative eGFR $<60 \mathrm{ml} / \mathrm{min} / 1.73 \mathrm{~m}^{2}$ was one of the independent predictors of worse disease-specific and recurrence-free survival rate as well as positive surgical margins. Other inflammatory indices such as CAR, NLR, PLR, GPS, and serum fibrinogen levels were found to be independent factors for shortened disease-specific and recurrence-free survival time in univariate analyses, but not for worse survival times in multivariate analyses using Cox proportional hazards models. Based on this finding, we designated preoperative eGFR $<60 \mathrm{ml} / \mathrm{min} / 1.73 \mathrm{~m}^{2}$ as a prognosticator of worse survival in addition to positive surgical margins, which were also an independent factor for worse disease-specific and recurrence-free survival rates in multivariate analyses.

CKD has been related to worse recurrence-free and/or disease-specific survival in patients with several urinary tract or urogenital carcinomas such as renal cell carcinoma, bladder urothelial carcinoma, and prostate carcinoma (23-25). Preoperative eGFR $<50 \mathrm{ml} / \mathrm{min} / 1.73 \mathrm{~m}^{2}$ as well as an inflammatory status indicated a poor prognosis in patients with UTUC (26). The present study also revealed that inflammatory markers such NLR and PLR were related to poor prognosis in univariate analysis, but not in multivariate analysis, although eGFR $<60 \mathrm{ml} / \mathrm{min} / 1.73 \mathrm{~m}^{2}$ was found to be significantly associated with worse disease-specific and recurrence-free survival rates in patients with UTUC who underwent radical nephroureterectomy in multivariate analysis. In addition, others suggested CKD or end-stage renal disease may be involved in the progression or aggressiveness of UTUC, i.e., decreasing disease-specific and/or recurrence-free survival (27-29). Another study has suggested that UTUC patients with CKD undergoing hemodialysis lack the immune cells that recognize the tumor-associated antigens, thereby resulting in the acceptance of tumor progression under the status of immunological suppression (30). These findings suggested that CKD is associated with the aggressiveness of UTUC in several studies, including our study. 
Table II. Univariate and multivariate analyses of independent factors for disease-specific survival.

\begin{tabular}{|c|c|c|c|c|c|c|}
\hline \multirow[b]{2}{*}{ A, Pathological parameters } & \multicolumn{2}{|c|}{ Univariate } & \multicolumn{4}{|c|}{ Multivariate } \\
\hline & HR & P-value & HR & & & P-value \\
\hline Age $(\geq 71$ or $<71$ years $)$ & 1.502 & 0.165 & & & & \\
\hline Sex (men or women) & 0.832 & 0.569 & & & & \\
\hline Urine cytology (positive or negative) & 1.971 & 0.034 & 1.479 & 0.679 & 3.398 & 0.330 \\
\hline Tumor histology (UC alone or with other component) & 2.895 & 0.002 & 1.371 & 0.514 & 3.380 & 0.514 \\
\hline Pathological $\mathrm{T}$ stage $(\geq \mathrm{T} 3$ or $\leq \mathrm{T} 2)$ & 4.686 & $<0.001$ & 1.853 & 0.750 & 4.835 & 0.183 \\
\hline Tumor grade (high or PUNLMP/low) & 5.056 & $<0.001$ & 1.824 & 0.643 & 6.025 & 0.268 \\
\hline Lymph node metastasis (positive or negative) & 5.066 & $<0.001$ & 1.021 & 0.300 & 3.150 & 0.972 \\
\hline Ureter involvement (positive or negative) & 1.329 & 0.339 & & & & \\
\hline Surgical margins (positive or negative) & 2.904 & 0.004 & 2.401 & 1.044 & 5.255 & 0.040 \\
\hline Lymphovascular invasion (positive or negative) & 7.029 & $<0.001$ & 2.366 & 0.920 & 6.376 & 0.074 \\
\hline History of bladder cancer (present or absent) & 1.046 & 0.893 & & & & \\
\hline Carcinoma in situ (positive or negative) & 0.676 & 0.429 & & & & \\
\hline Hydronephrosis (positive or negative) & 1.657 & 0.109 & & & & \\
\hline Surgical procedure (open or laparoscopic) & 1.463 & 0.209 & & & & \\
\hline
\end{tabular}

\begin{tabular}{|c|c|c|c|c|c|c|}
\hline \multirow{3}{*}{$\begin{array}{l}\text { B, Clinical parameters } \\
\text { Preoperative eGFR }(<60 \text { or } \geq 60)\end{array}$} & \multicolumn{2}{|c|}{ Univariate } & \multicolumn{4}{|c|}{ Multivariate } \\
\hline & \multirow{2}{*}{$\begin{array}{c}\text { HR } \\
3.259\end{array}$} & \multirow{2}{*}{$\begin{array}{l}\text { P-value } \\
<0.001\end{array}$} & \multirow{2}{*}{$\begin{array}{l}\mathrm{HR} \\
2.371\end{array}$} & \multicolumn{2}{|c|}{ P-value } & \multirow{2}{*}{$\frac{\text { P-value }}{0.044}$} \\
\hline & & & & 1.024 & 5.898 & \\
\hline Preoperative CAR $(\geq 0.079$ or $<0.079)$ & 2.528 & 0.002 & 1.343 & 0.523 & 3.446 & 0.538 \\
\hline Preoperative NLR $(\geq 2.035$ or $<2.035)$ & 2.371 & 0.009 & 1.598 & 0.643 & 4.268 & 0.318 \\
\hline Preoperative PLR $(\geq 165$ or $<165)$ & 2.200 & 0.008 & 0.964 & 0.463 & 2.011 & 0.922 \\
\hline Preoperative GPS ( $\geq 1$ or 0 ) & 3.088 & 0.003 & 0.985 & 0.303 & 2.941 & 0.979 \\
\hline Fibrinogen $(\geq 337$ or $<337)$ & 4.199 & $<0.001$ & 1.632 & 0.618 & 4.240 & 0.321 \\
\hline
\end{tabular}

HR, hazard ratio; CI, confidence interval; UC, urothelial carcinoma; CIS, carcinoma in situ; PUNLMP, papillary urothelial neoplasm of low malignant potential; eGFR, estimated glomerular filtration rate $\left(\mathrm{ml} / \mathrm{min} / 1.73 \mathrm{~m}^{2}\right)$; CAR, C-reactive protein to albumin ratio; NLR, neutrophil to lymphocyte ratio; PLR, platelet to lymphocyte ratio; GPS, Glasgow prognostic score.
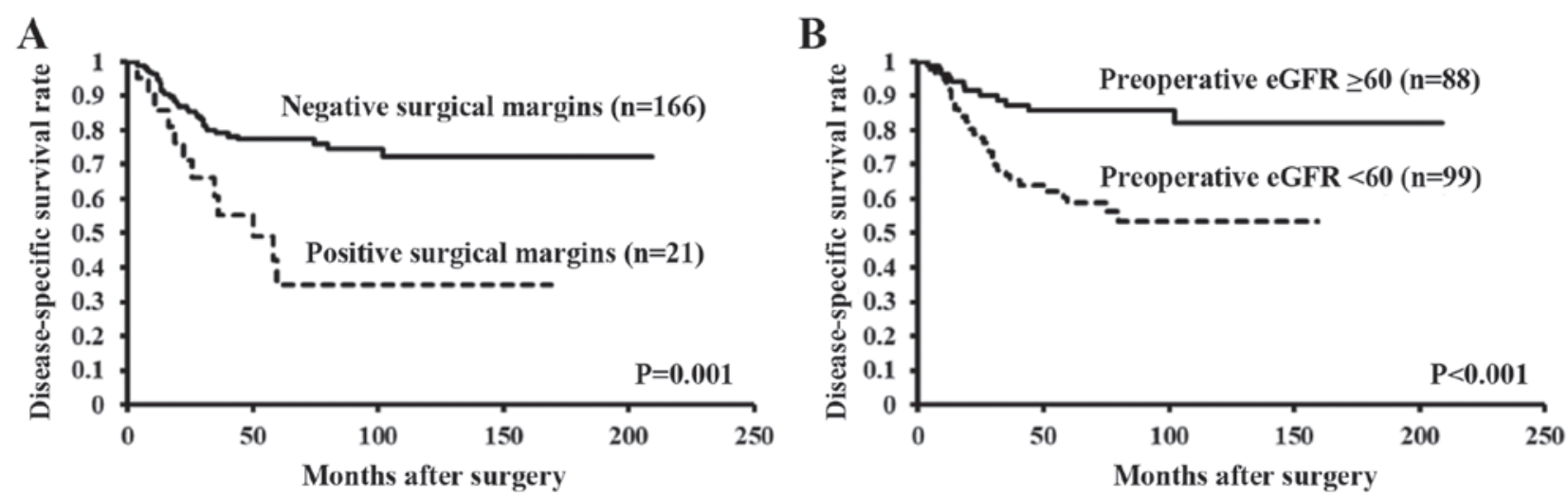

Figure 2. There is a significant difference in the time to disease-specific mortality between patients with and without (A) positive surgical margins and (B) preoperative eGFR $<60 \mathrm{ml} / \mathrm{min} / 1.73 \mathrm{~m}^{2}$. eGFR, estimated glomerular filtration rate.

The pathophysiological mechanism of the contribution of CKD to poor prognosis in patients with UTUC remains undermined despite some postulated reasons for the association of CKD with high incidence of chronic irritation of the bladder, decrease in urinary washout, atrophic change in the bladder, and uremia (31-33). In addition, an immune defect could be one of the most commonly mentioned mechanisms in patients with CKD who show immune 
Table III. Univariate and multivariate analyses of independent factors for recurrence-free survival.

\begin{tabular}{|c|c|c|c|c|c|c|}
\hline \multirow[b]{2}{*}{ A, Pathological parameters } & \multicolumn{2}{|c|}{ Univariate } & \multicolumn{4}{|c|}{ Multivariate } \\
\hline & $\mathrm{HR}$ & P-value & HR & & & P-value \\
\hline Age $(\geq 71$ or $<71)$ & 1.473 & 0.162 & & & & \\
\hline Sex (men or women) & 0.727 & 0.289 & & & & \\
\hline Urine cytology (positive or negative) & 1.499 & 0.166 & & & & \\
\hline Tumor histology (UC alone or with other component) & 2.908 & 0.001 & 1.692 & 0.706 & 3.962 & 0.234 \\
\hline Pathological $\mathrm{T}$ stage $(\geq \mathrm{T} 3$ or $\leq \mathrm{T} 2$ ) & 4.965 & $<0.001$ & 2.010 & 0.911 & 4.719 & 0.085 \\
\hline Tumor grade (high or PUNLMP/low) & 5.657 & $<0.001$ & 2.934 & 1.069 & 9.570 & 0.036 \\
\hline Lymph node metastasis (positive or negative) & 5.829 & $<0.001$ & 1.815 & 0.611 & 4.940 & 0.271 \\
\hline Ureter involvement (positive or negative) & 1.300 & 0.347 & & & & \\
\hline Surgical margins (positive or negative) & 3.210 & 0.001 & 4.477 & 2.042 & 9.469 & $<0.001$ \\
\hline Lymphovascular invasion (positive or negative) & 6.190 & $<0.001$ & 2.615 & 1.180 & 5.969 & 0.018 \\
\hline History of bladder cancer (present or absent) & 1.079 & 0.808 & & & & \\
\hline Carcinoma in situ (positive or negative) & 0.590 & 0.273 & & & & \\
\hline Hydronephrosis (positive or negative) & 1.723 & 0.065 & & & & \\
\hline Surgical procedure (open or laparoscopic) & 1.698 & 0.065 & & & & \\
\hline
\end{tabular}

\begin{tabular}{|c|c|c|c|c|c|c|}
\hline \multirow{3}{*}{$\begin{array}{l}\text { B, Clinical parameters } \\
\text { Preoperative eGFR }(<60 \text { or } \geq 60)\end{array}$} & \multicolumn{2}{|c|}{ Univariate } & \multicolumn{4}{|c|}{ Multivariate } \\
\hline & \multirow{2}{*}{$\begin{array}{c}\mathrm{HR} \\
3.049\end{array}$} & \multirow{2}{*}{$\begin{array}{l}\text { P-value } \\
<0.001\end{array}$} & \multirow{2}{*}{$\begin{array}{c}\mathrm{HR} \\
2.362\end{array}$} & \multicolumn{2}{|c|}{$95 \% \mathrm{CI}$} & \multirow{2}{*}{$\frac{\text { P-value }}{0.034}$} \\
\hline & & & & 1.067 & 5.592 & \\
\hline Preoperative CAR $(\geq 0.079$ or $<0.079)$ & 2.265 & 0.004 & 1.091 & 0.467 & 2.480 & 0.838 \\
\hline Preoperative NLR $(\geq 2.035$ or $<2.035)$ & 1.846 & 0.040 & 1.488 & 0.669 & 3.477 & 0.334 \\
\hline Preoperative PLR $(\geq 165$ or $<165)$ & 1.939 & 0.019 & 0.877 & 0.434 & 1.755 & 0.711 \\
\hline Preoperative GPS ( $\geq 1$ or 0 ) & 3.011 & 0.003 & 1.220 & 0.407 & 3.384 & 0.711 \\
\hline Fibrinogen ( $\geq 337$ or <337) & 3.545 & $<0.001$ & 1.160 & 0.523 & 2.566 & 0.713 \\
\hline
\end{tabular}

HR, hazard ratio; CI, confidence interval; UC, urothelial carcinoma; CIS, carcinoma in situ; PUNLMP, papillary urothelial neoplasm of low malignant potential; eGFR, estimated glomerular filtration rate $\left(\mathrm{ml} / \mathrm{min} / 1.73 \mathrm{~m}^{2}\right)$; CAR, C-reactive protein to albumin ratio; NLR, neutrophil to lymphocyte ratio; PLR, platelet to lymphocyte ratio; GPS, Glasgow prognostic score.
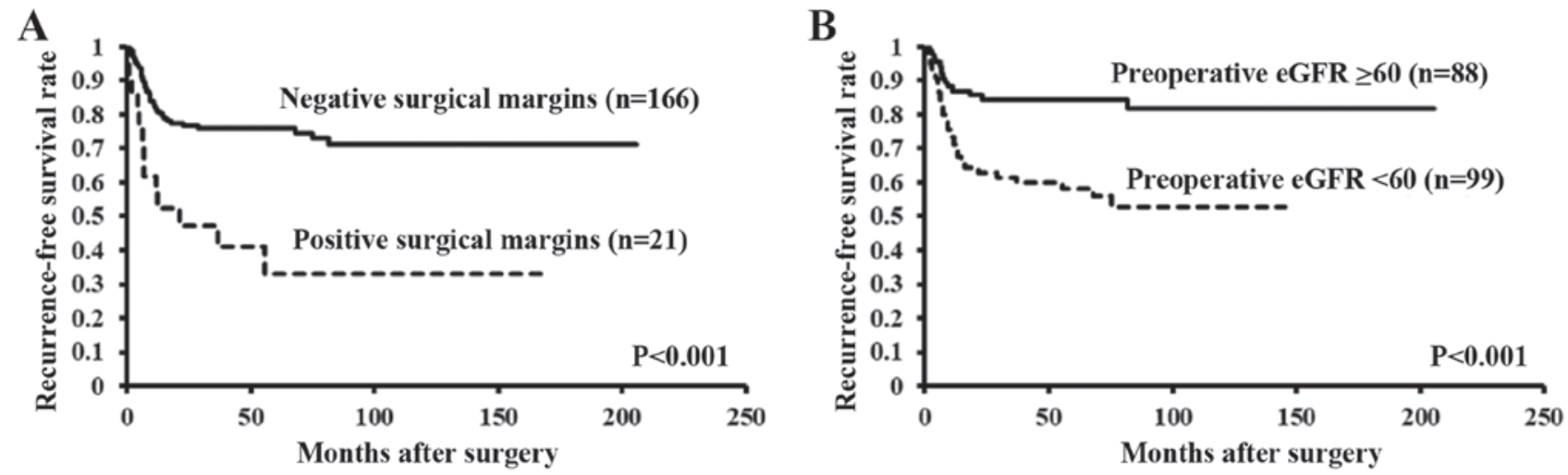

Figure 3. Time taken for extraurothelial recurrence to occur significantly differed in patients with and without (A) positive surgical margins and (B) preoperative eGFR $<60 \mathrm{ml} / \mathrm{min} / 1.73 \mathrm{~m}^{2}$. eGFR, estimated glomerular filtration rate.

dysfunction characterized by immunosuppression (34). The impaired ability of DNA to repair the cells, deficiencies in adequate nutrition, and chronic infection in urinary tract are also likely reasons for the association of CKD with poorer prognostic survival $(35,36)$. Moreover, several inflammatory markers such as NLR and PLR have been 

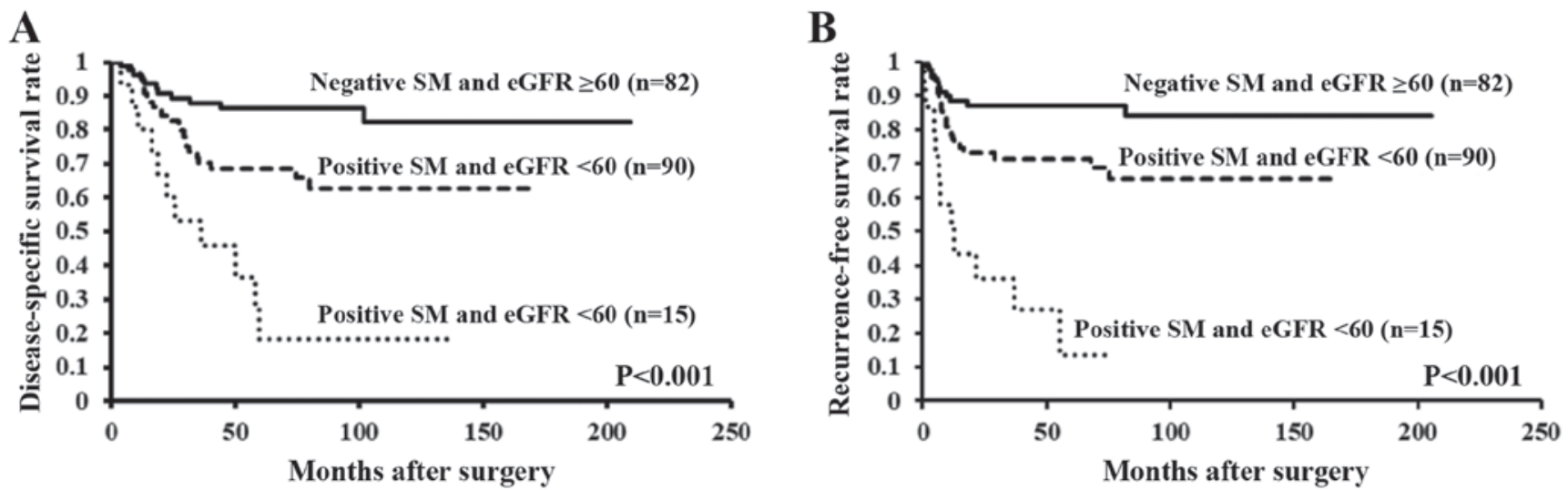

Figure 4. There is a significant difference in time to (A) disease-specific mortality or (B) extraurothelial recurrence in patients with both positive SM and preoperative eGFR $<60 \mathrm{ml} / \mathrm{min} / 1.73 \mathrm{~m}^{2}$, those with either factor, and those with neither factor. SM, surgical margins; eGFR, estimated glomerular filtration rate.

reported to play important roles as prognosticators in UTUC patients who underwent radical nephroureterectomy (37). In fact, a study indicated that CKD is similar in status to inflammation (38).

Positive surgical margins may play a critical role as one of the independent predictors of shorter time to disease-specific death or extraurothelial recurrence in patients undergoing radical nephroureterectomy for UTUC $(26,39)$. Open extravesical or open intravesical bladder cuff excision has been performed for all patients enrolled in the present study; however, there was no significant difference in marginal positivity of the distal excised ureter (data not shown). Recurrence and metastases rates are reported to be clinically similar, regardless of the method of bladder cuff excision performed during laparoscopic radical nephroureterectomy (40).

This study had some potential limitations. First, our sample size was relatively small although we evaluated the rates of disease-specific and recurrence-free survivals as our outcome endpoint. With a longer follow-up and a larger subject population, the statistical strength of our study should be reinforced, allowing us to comment on precise prognostic outcomes. Second, we could not verify the-cause-and-effect relation between $\mathrm{CKD}$ and the worse-survival rate in patients with UTUC, although the possible implications about patients with these two conditions were suggested. Third, the serum fibrinogen levels were not estimated in all patients. However, the patients in whom the serum fibrinogen levels were not measured were excluded from statistical analyses. Therefore, we believe that the statistical evaluation in the present study is accurate. Despite these limitations, we speculate that CKD prior to nephroureterectomy in addition to positive surgical margins could provide us additional information about the possibility of worse disease-specific and recurrence-free survival rates.

UTUC patients with CKD showed the worse diseasespecific and recurrence-free survival rates in this study. In addition, patients with positive surgical margins also have poor survival rates. Therefore, we recommend that patients with UTUC who have both CKD and positive surgical margins should be monitored carefully after radical nephroureterectomy.

\section{Acknowledgements}

Not applicable.

\section{Funding}

The present study was funded in part by a research grant from National Defense Medical College (grant no. 21096).

\section{Availability of data and materials}

The datasets used and/or analyzed during the current study are available from the corresponding author on reasonable request.

\section{Authors' contributions}

KK, JA, AH, MK, MS, AM, ST, AS and KI were involved in the conception and design of the study. KK collected and analyzed the data, and drafted the manuscript. KK and $\mathrm{KI}$ reviewed and edited the manuscript. All authors have read and approved the final manuscript.

\section{Ethics approval and consent to participate}

All procedures performed in the present study were in accordance with the ethical standards of National Defense Medical College (Saitama, Japan; no. 2734). The study protocol (ID 2734) was accepted on June 14, 2017, by our institutional ethics committee (National Defense Medical College, Saitama, Japan), and an opt-out approach on the web page of the National Defense Medical College was used instead of collecting written informed consent from all participants.

\section{Patient consent for publication}

Not applicable.

\section{Competing interests}

The authors declare that they have no competing interests. 


\section{References}

1. Babjuk M,Böhle A,Burger M,Capoun O, Cohen D, Compérat EM Hernández V, Kaasinen E, Palou J, Rouprêt M, et al: EAU Guidelines on non-muscle-invasive urothelial carcinoma of the bladder: Update 2016. Eur Urol 71: 447-461, 2017.

2. Siegel R, Miller K and Jemal A: Cancer statistics, 2015. CA Cancer J Clin 65: 5-29, 2015.

3. Munoz JJ and Ellison LM: Upper tract urothelial neoplasms: Incidence and survival during the last 2 decades. J Urol 164 $1523-1525,2000$.

4. Cosentino M, Palou J, Gaya JM, Breda A, Rodriguez-Faba O and Villavicencio-Mavrich H: Upper urinary tract urothelial cell carcinoma: Location as a predictive factor for concomitant bladder carcinoma. World J Urol 31: 141-145, 2013.

5. Seisen T, Granger B, Colin P, Léon P, Utard G, Renard-Penna R, Compérat E, Mozer P, Cussenot O, Shariat SF and Rouprêt M: A systematic review and meta-analysis of clinicopathologic factors linked to intravesical recurrence after radical nephroureterectomy to treat upper tract urothelial carcinoma. Eur Urol 67: 1122-1133, 2015.

6. Novara G, De Marco V, Dalpiaz O, Galfano A, Bouygues V, Gardiman M, Martignoni G, Patard JJ, Artibani W and Ficarra V: Independent predictors of contralateral metachronous upper urinary tract transitional cell carcinoma after nephroureterectomy: Multi-institutional dataset from three European centers Int J Urol 16: 187-191, 2009.

7. Li WM, Shen JT, Li CC, Ke HL, Wei YC, Wu WJ, Chou YH and Huang $\mathrm{CH}$ : Oncologic outcomes following three different approaches to the distal ureter and bladder cuff in nephroureterectomy for primary upper urinary tract urothelial carcinoma. Eur Urol 57: 963-969, 2010.

8. Matas AJ, Simmons RL, Kjellstrand CM, Buselmeier TJ and Najarian JS: Increased incidence of malignancy during chronic renal failure. Lancet 1: 883-886, 1975 .

9. Cengiz K: Increased incidence of neoplasia in chronic renal failure (20-year experience). Int Urol Nephrol 33: 121-126, 2002

10. Stewart JH: Cancers of the kidney and urinary tract in patients on dialysis for end-stage renal disease: Analysis of data from the United states, Europe, and Australia and New Zealand. J Am Soc Nephrol 14: 197-207, 2003.

11. Ito K, Kuroda K, Asakuma J,Hamada S, Tasaki S, Tasaki S, Sato A Horiguchi A, Seguchi K and Asano T: Preoperative risk factors for extraurothelial recurrence in patients with ureteral cancer treated with radical nephroureterectomy. J Urol 191: 1685-1692, 2014.

12. Kuroda K, Asakuma J, Horiguchi A, Tasaki S, Yoshii H, Sato A, Ito K, Seguchi K, Sumitomo M and Asano T: Prognostic factors for upper urinary tract urothelial carcinoma after nephroureterectomy. Urol Int 88: 225-231, 2012.

13. Bolenz C, Shariat SF, Fernández MI, Margulis V, Lotan Y, Karakiewicz P, Remzi M, Kikuchi E, Zigeuner R, Weizer A, et al: Risk stratification of patients with nodal involvement in upper tract urothelial carcinoma: Value of lymph-node density. BJU Int 103: 302-306, 2009.

14. Sobin L, Gospodarowicz M and Wittekind C: TNM Classification of Malignant Tumours. 7th edition, 2009.

15. John E, Guido S, Jonathan E and Isabell S: Pathology and Genetics: Tumours of the Urinary System and Male Genital System (IARC WHO Classification of Tumours), 2004.

16. Qu JL, Qu XJ, Li Z, Zhang JD, Liu J, Teng YE, Jin B, Zhao MF, Yu P, Shi J, et al: Prognostic model based on systemic inflammatory response and clinicopathological factors to predict outcome of patients with Node-Negative gastric cancer. PLoS One 10: e0128540, 2015

17. Yuksel OH, Akan S, Uukmez A, Yildirim C, Sahin A and Verit A: Preoperative glasgow prognostic score as a predictor of primary bladder cancer recurrence. Mol Clin Oncol 5: 201-206, 2016.

18. Imai E, Horio M, Nitta K, Yamagata K, Iseki K, Tsukamoto $Y$, Ito S, Makino H, Hishida A and Matsuo S: Modification of the modification of diet in renal disease (MDRD) Study equation for Japan. Am J Kidney Dis 50: 927-937, 2007.

19. Kang M, Jeong CW, Kwak C, Kim HH and Ku JH: Preoperative neutrophil-lymphocyte ratio can significantly predict mortality outcomes in patients with non-muscle invasive bladder cancer undergoing transurethral resection of bladder tumor Oncotarget 8: 12891-12901, 2016.

20. Uemura K, Kawahara T, Yamashita D, Jikuya R, Abe K, Tatenuma T, Yokomizo Y, Izumi K, Teranishi JI, Makiyama K, et al: Neutrophil-to-lymphocyte ratio predicts prognosis in castration-resistant prostate cancer patients who received cabazitaxel chemotherapy. Biomed Res Int 2017: 7538647, 2017.
21. Gunes A, Yigit M, Tok L and Tok O: Neutrophil to lymphocyte ratio in patients with nonarteritic anterior Ischemic optic neuropathy. Korean J Ophthalmol 31: 159-164, 2017.

22. Kasuga J, Kawahara T, Takamoto D, Fukui S, Tokita T, Tadenuma T, Narahara M, Fusayasu S, Terao H, Izumi K, et al: Increased neutrophil-to-lymphocyte ratio is associated with disease-specific mortality in patients with penile cancer. BMC Cancer 16: 396, 2016.

23. Li CE, Chien CS, Chuang YC, HP T and CH K: Chronic kidney disease as an important risk factor for tumor recurrences, progression and overall survival in primary non-muscle-invasive bladder cancer. Int Urol Nephrol 48: 993-999, 2016.

24. Kim YW, Kim WT, Yun SJ, Lee SC, Kim WJ, Ha YS, Park YH, Kang SH, Hong SH, Kwon TG, et al: Preoperative chronic kidney disease status is an independent prognostic factor in patients with renal cell carcinoma. Ann Surg Oncol 22: 4098-4103, 2015.

25. Tollefson MK, Boorjian SA, Gettman MT, Rangel LJ, Bergstralh EJ and Karnes RJ: Preoperative estimated glomerular filtration rate predicts overall mortality in patients undergoing radical prostatectomy. Urol Oncol 31: 1483-1488, 2013.

26. Morizane S, Yumioka T, Yamaguchi N, Masago T, Honda M, Sejima T and Takenaka A: Risk stratification model, including preoperative serum C-reactive protein and estimated glomerular filtration rate levels, in patients with upper urinary tract urothelial carcinoma undergoing radical nephroureterectomy. Int Urol Nephrol 47: 1335-1341, 2015.

27. Li CC, Chang TH, Wu WJ, Ke HL, Huang SP, Tsai PC, Chang SJ, Shen JT, Chou YH and Huang CH: Significant predictive factors for prognosis of primary upper urinary tract cancer after radical nephroureterectomy in Taiwanese patients. Eur Urol 54: 1127-1134, 2008.

28. Wu CF, Chang PL, Chen CS, Chuang CK, Weng HH and Pang ST: The outcome of patients on dialysis with upper urinary tract transitional cell carcinoma. J Urol 176: 477-481, 2006.

29. Yu HS, Hwang JE, Chung HS, Cho YH, Kim MS, Hwang EC, Oh KJ, Kim SO, Jung SI, Kang TW, et al: Is preoperative chronic kidney disease status associated with oncologic outcomes in upper urinary tract urothelial carcinoma? A multicenter propensity score-matched analysis. Oncotarget 8: 66540-66549, 2017.

30. Li WM, Li CC, Ke HL, Wu WJ, Huang CN and Huang CH: The prognostic predictors of primary ureteral transitional cell carcinoma after radical Nephroureterectomy. J Urol 182: 451-458, 2009.

31. Ou JH, Pan CC, Lin JS, Tzai TS, Yang WH, Chang CC, Cheng HL, Lin YM and Tong YC: Transitional cell carcinoma in dialysis patients. Eur Urol 37: 90-94, 2000.

32. Chang CH, Yang CM and Yang AH: Renal diagnosis of chronic hemodialysis patients with urinary tract transitional cell carcinoma in Taiwan. Cancer 109: 1487-1492, 2007.

33. Chen KS, Lai MK, Huang CC, Chu SH and Leu ML: Urologic cancers in uremic patients. Am J Kidney Dis 25: 694-700, 1995.

34. Kato S, Chmielewski M, Honda H, Pecoits-Filho R, Matsuo S, Yuzawa Y, Tranaeus A, Stenvinkel P and Lindholm B: Aspects of immune dysfunction in end-stage renal disease. Clin J Am Soc Nephrol 3: 1526-1533, 2008.

35. Vamvakas S, Bahner U and Heidland A: Cancer in end-stage renal disease: Potential factors involved. Am J Nephrol 18: 89-95, 1998.

36. Stopper H, Meysen T, Bockenforde A, Bahner U, Heidland A and Vamvakas S: Increased genomic damage in lymphocytes of patients before and after long-term maintenance hemodialysis therapy. Am J Kidney Dis 34: 433-437, 1999.

37. Song X, Zhang GM, Ma XC, Luo L, Li B, Chai DY and Sun L: Comparison of preoperative neutrophil-lymphocyte, lymphocyte-monocyte, and platelet-lymphocyte ratios in patients with upper urinary tract urothelial carcinoma undergoing radical nephroureterectomy. Onco Targets Ther 9: 1399-1407, 2016.

38. Keller CR, Odden MC, Fried LF, Newman AB, Angleman S, Green CA, Cummings SR, Harris TB and Shlipak MG: Kidney function and markers of inflammation in elderly persons without chronic kidney disease: The health, aging, and body composition study. Kidney Int 71: 239-244, 2007.

39. Colin P, Ghoneim TP, Nison L, Seisen T, Lechevallier E, Cathelineau X, Ouzzane A, Zerbib M, Long JA, Ruffion A, et al: Risk stratification of metastatic recurrence in invasive upper urinary tract carcinoma after radical nephroureterectomy without lymphadenectomy. World J Urol 32: 507-512, 2014.

40. Allard CB, Alamri A, Dason S, Farrokhyar F, Matsumoto ED and Kapoor A: The method of bladder cuff excision during laparoscopic radical nephroureterectomy does not affect oncologic outcomes in upper tract urothelial carcinoma. World J Urol 31: 175-181, 2013. 